\title{
Paediatric contacts with the UK out-of-hours primary care service and contact outcomes: a regional service evaluation
}

\author{
George Edwards $^{1 *} \mathbb{D}$, Rachel Brettell ${ }^{1}$, Chris Bird² ${ }^{2}$ Helen Hunt ${ }^{3}$, Dan Lasserson ${ }^{4}$ and Gail Hayward ${ }^{1}$
}

\begin{abstract}
Background: Demand on hospital emergency departments for paediatric problems is increasing. However, the volume and nature of paediatric health demands placed on other parts of the urgent care system have not been explored. This understanding is an important first step in developing and improving out-of-hospital care. We aimed to describe the volume, nature, and outcomes of paediatric contacts with out-of-hours general practice (OOH GP). We performed a retrospective service evaluation using data from 12 months of paediatric patient contacts with the Oxfordshire OOH GP service.

Methods: A database of contacts with the Oxfordshire OOH GP service was created for a 12 month period from December 2014 to November 2015. Descriptive statistics were calculated using SPSS Version 25.

Results: 27,455 contacts were made by 18,987 individuals during a 12 month period. The majority of these were for children aged under 5 . Over $70 \%$ of contacts were at the weekend. The peak contact period was between 18:30 and 21:30. Over $40 \%$ of contacts resulted in advice only (no onward referral, requirement for GP follow up, or prescription). $19.7 \%$ of contacts resulted in an antibiotic prescription, most commonly those linked with ear, chest, and throat infections.

Discussion: Paediatric contacts with the Oxfordshire OOH GP service were predominantly in younger age groups and in the evening, with $19.7 \%$ resulting in an antibiotic prescription. Almost half of the contacts had no follow up or prescription, suggesting non-prescribing health care professionals could be involved in providing care in $\mathrm{OOH}$ GP. Further research should consider how children and their parents can be best supported to optimise $\mathrm{OOH}$ consulting.
\end{abstract}

\section{Background}

Demand on hospital emergency departments for paediatric problems is increasing [1]' [2]' [3]. At one centre, attendances for medical problems in the Emergency Department (ED) rose $42 \%$ in the 10 years between 1997 and 8 and $2007-8$ and the $0-4$ years age group account for almost $70 \%$ of these contacts [3]. However, amongst children aged under 16 , almost $30 \%$ of these contacts

\footnotetext{
* Correspondence: George.edwards@phc.ox.ac.uk

${ }^{1}$ Nuffield Department of Primary Care Health Sciences, Radcliffe Observatory Quarter, Woodstock Road, Oxford OX2 6GG, England

Full list of author information is available at the end of the article
}

may be better managed in primary and out-of-hospital settings [4]' [5]' [6], including out-of-hours general practice (OOH GP).

In the UK, the provision of primary care services outside core contracted hours is an integral NHS service [7]' [8]. In 2013-2014, 5.8 million cases were handled by OOH GP in England resulting in 3.3 million face-to-face consultations, including 800,000 home visits [9]. This service provides access to urgent primary care between 18:30 and 08:00 on weekdays, and all day on weekends and on bank holidays. It is an important alternative to a visit to the emergency department. Appointments with 
the OOH GP service are booked vie the free-to-use NHS 111 telephone advice line, where trained call handlers use the NHS pathways algorithm to direct patients to self-care advice or the most appropriate service for their needs.

Understanding the nature and outcomes of contacts with NHS services is key to evaluating and improving these services. Paediatric contacts with NHS services have been described in relation to Emergency Departments (ED) or Urgent Care Centres (UCC) [10-12] . In $\mathrm{OOH}$ primary care services in eight European countries, up to a third of contacts were shown to be for children under the age of 18 [13] and a third of out of hours consultations amongst under $12 \mathrm{~s}$ were fever related in a Dutch OOH GP service [14]. Of these, $7.6 \%$ were referred to secondary care [14]. In Denmark 27\% of children aged 0-5 presenting to $\mathrm{OOH}$ GP received a prescription, $74 \%$ of which were for antibiotics, and 7.4\% of children were referred to a nearby hospital [15].

To date, there has been no description of paediatric contacts, or the outcome of these contacts, with $\mathrm{OOH}$ GP in the UK. This understanding is critical to inform new approaches to managing the rising demand for acute paediatric assessment across urgent and unscheduled care, and ensuring safe and appropriate management. We aimed to characterise the nature, timing, and outcomes of paediatric contacts with the OOH GP using a large dataset of patient contacts with the Oxfordshire $\mathrm{OOH}$ service, which provides care to a population of over 600,000 people.

\section{Methods}

A database of all intended patient contacts with the Oxfordshire $\mathrm{OOH}$ GP service, which provides care to a population of over 600,000 people, over 1 year from 1 December 2014 to 30 November 2015 was created from the $\mathrm{OOH}$ Electronic Record System used by clinicians (Adastra).

Service data included contact type, contact outcome, date, clinical codes assigned and prescriptions issued. Demographic data included patient sex, age, and a deprivation index (the Index of Multiple Deprivation (IMD)). Lower IMD scores indicate lower levels of deprivation. Contacts were coded with their final contact type: a 'telephone consultation', a 'base visit' (patient assessed at $\mathrm{OOH}$ base), a 'home visit' (patient assessed in their home), or a "111 appointment to book" for patients the 111 service have determined an appointment is needed but cannot be booked (for example due to appointments being full, or the triaging service lacking access to appointment system). This results in a contact with the OOH GP which may be a base visit, telephone consultation, or home visit.
Timings of calls were classified as evening 18:30-23: $59 \mathrm{~h}$, night 00:00-07:59 h, and daytime (on weekends and bank holidays) 08:00-18:29 h. The weekend period was classified as 18:30 h Friday until 08:00 h Monday, whilst contacts classified as 'Bank Holiday' were those occurring during daytime hours on each Bank Holiday.

At the end of each consultation, clinicians assign at least one clinical code (for example 'H05z. Upper respiratory infection. NOS'), which were used in this study to determine clinical presentation for that contact. These clinical codes were validated by two members of the direct care team based on previous coding validity studies [16]. The positive predictive value (PPV) of the clinical code for medical diagnosis or conclusion was $92.6 \%$ [8]. In order to facilitate analysis these codes translated into International Classification of Primary Care (ICPC) codes by two clinically qualified authors $(\mathrm{GH}, \mathrm{RB})$ (supplementary Table 1). Codes which may indicate an infection were noted. An additional code, not available in the ICPC, was added for contacts indicating the patients did not attend (DNA). A small number of contacts $(n=264$, $1 \%)$ had "NULL" as their clinical code. These contacts were removed from the dataset.

Clinicians also detail any prescriptions issued during the consultation in up to six fields. Prescriptions were grouped into 21 categories and 79 sub-categories for the purposes of analysis. These are detailed in supplementary Table 2.

Each contact is coded with an 'Outcome'. There were 19 outcome codes, which were condensed into 9 outcome categories. These are detailed in supplementary Table 3.

Descriptive statistics were calculated in SPSS version 25. Analyses were undertaken at the contact level unless otherwise stated.

\section{Results}

Between 1 December 2014 and 30 November 2015, 67, 942 patients made 102,876 contacts with the Oxfordshire OOH GP service. Of these, 27,455 contacts (26.69\%) made by 18,987 individuals $(29.95 \%)$ were for children under the age of 18 . Of these individuals, 13, 833 (72.9\%) had one contact, 3341 (17.6\%) had two contacts, and $1813(9.5 \%)$ had three or more contacts. See Fig. 1 for details.

The median age of children contacting the OOH GP service was 3.1 (IQR 1.1-7.0). In the twelve month period, 6136 contacts (22.3\%) were for children under the age of one, and 11,852 (43.2\%) of contacts were for children aged between 1 and 4 years. Children aged 511 account for 6118 contacts $(22.3 \%)$, whilst there were 3349 contacts $(12.2 \%)$ for children aged 12 and over. The median index of multiple deprivation (IMD) score was 10.79 (IQR 6.15-18.24). 


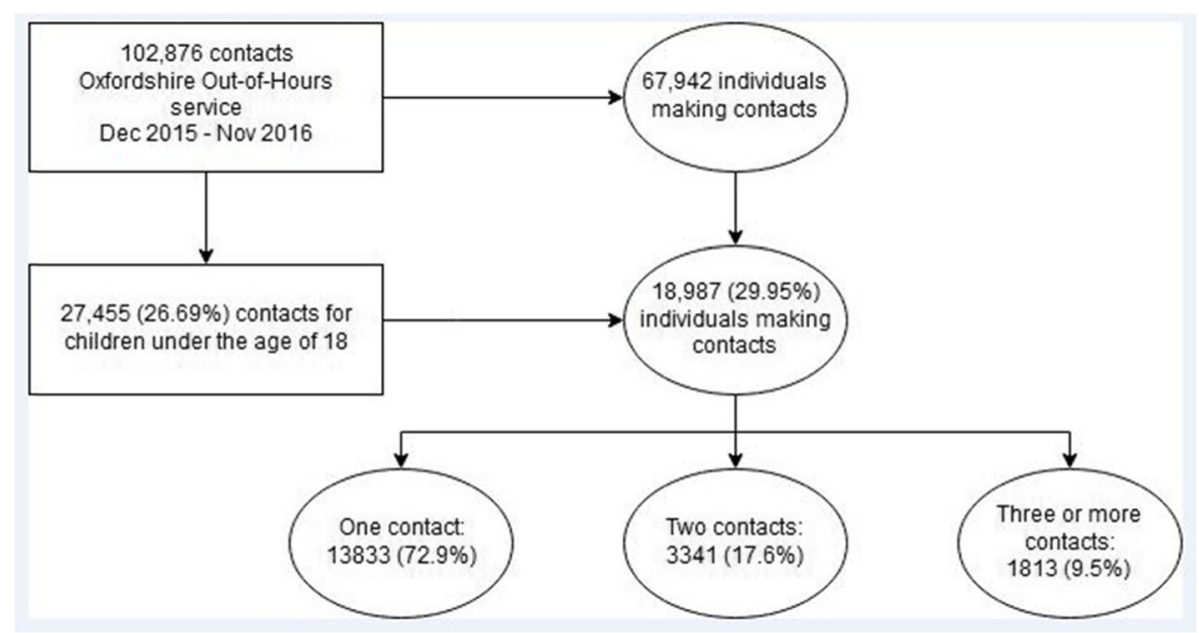

Fig. 1 patient flow diagram

$48.7 \%$ of contacts were for female patients, and of these the median age in years was 3.5 (IQR 1.2-8.1). The median age of male patients was 2.8 (IQR 1.1-6.0). Figure 2 shows the age distribution, in whole years, of all paediatric contacts with the Oxfordshire OOH GP service during the 12 month period. At younger ages, there were slightly more male patients $(54.5$ and $54.0 \%$ in the $0-1$ and $1-5$ age groups respectively). In contrast, in the 12-17 age group almost twice as many female patients contacted the service $(63.5 \%$ of contacts in this age group).

\section{Contact types and timings}

The month with the greatest number of contacts was December, and July had the lowest number of contacts (Table 1). 19,260 (70.2\%) contacts were at the weekend and 870 (3.2\%) were on a Bank Holiday. 9103 (33.2\%) contacts were on a Saturday and 8048 (29.3\%) were made on a Sunday. During the week, Tuesdays and Wednesdays had the lowest proportion of contacts $(6.4 \%$ in both cases), followed by Thursday (7.0\%), Monday $(8.8 \%)$ and Friday (9.0\%).

There were 20,692 (75.4\%) base visits whilst 6603 (24.1\%) contacts were managed purely by telephone. There were $123(0.4 \%)$ home visits and $37(0.1 \%)$ "111 appt to book contacts" (contacts for which appointments cannot be booked within the time frame dictated by 111 and are passed onto the OOH GP service separately).

Figure 3 demonstrates the pattern of attendance during weekdays (top) and at the weekend or on Bank Holidays (bottom) divided by type of contact (excluding "111 appt to book"). Peak attendance was between 18:00 and 21:00. On non-bank holiday weekdays, 5089 contacts (73.4\%) were in the evening and 1749 (25.2\%) contacts

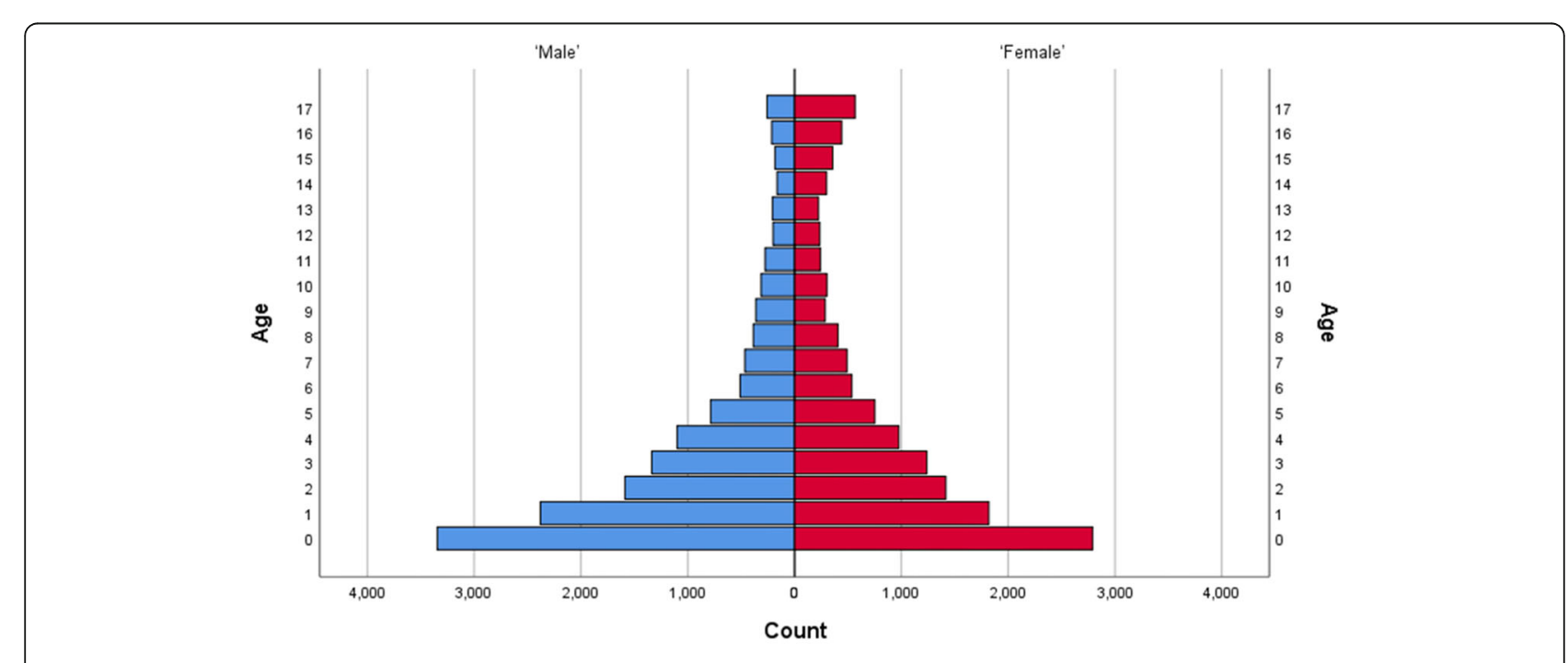

Fig. 2 Population pyramid of frequency of contact age by sex seen by the Oxfordshire OOH service from December 2014 to November 2015 
Table 1 The number and percentage of contacts in each month

\begin{tabular}{lcr}
\hline Month & Number of contacts & Percent \\
\hline December 2014 & 3522 & $12.8 \%$ \\
January 2015 & 2399 & $8.7 \%$ \\
February 2015 & 2407 & $8.8 \%$ \\
March 2015 & 2558 & $9.3 \%$ \\
April 2015 & 2307 & $8.4 \%$ \\
May 2015 & 2522 & $9.2 \%$ \\
June 2015 & 1819 & $6.6 \%$ \\
July 2015 & 1639 & $6.0 \%$ \\
August 2015 & 1668 & $6.1 \%$ \\
September 2015 & 1799 & $6.6 \%$ \\
October 2015 & 2136 & $7.8 \%$ \\
November 2015 & 2679 & $9.8 \%$ \\
Total & 27,455 & $100.0 \%$ \\
\hline
\end{tabular}

were in the night. In contrast at the weekend, 10779 (56.0\%) contacts were made during the day, 2021 (10.5\%) were during the night and 6457 (33.5\%) were during the evening.

\section{Reasons for contact}

Table 2 shows the frequency of contacts including at least one clinical code falling into each ICPC Chapter. The most common clinical category overall and in each age-category was 'Respiratory' (Chapter R), with related codes in 9280 (33.8\%) contacts. Other commonly arising chapters 'General and Unspecified' (Chapter A) ( $n=$ 5627, 20.5\%), 'Digestive' (Chapter D) (4181, 15.2\%), 'Skin' (Chapter S) (2635, 9.6\%), and 'Ear' (Chapter H) (2209, 8.0\%). $472(1.7 \%)$ of contacts were coded with a musculoskeletal code and this was most prevalent in children aged 12 and older. 82 (2.4\%) contacts for children aged 12 and over were coded with a psychiatric condition. Ninety-four of the 101 of children aged less than 1 with a psychological code had problems feeding.

The most common ICPC Codes were Upper Respiratory Tract Infection (R74) (14.3\% of contacts), Viral disease other/NOS (A77) (7.7\%), Fever (A03) (7.1\%), Tonsillitis Acute (R76) (4.9\%), and Acute otitis media/ myringitis (H71) (4.9\%) (see supplementary Table 4 for full details). Across the data set, 14,267 (52.0\%) individuals contacted the $\mathrm{OOH}$ GP service regarding an infection. Children aged 1-4 had the highest percentage of infection (59.6\%).

\section{Outcomes of contacts}

After 16,153 (58.8\%) contacts there was no documented requirement for follow up. After 11,359 (41.4\%) contacts there was no documented requirement for follow up and no prescription issued, considered as 'advice only' appointments. In $8394(30.6 \%)$ of contacts the patient was advised to contact their own GP, and there was a referral to secondary care in $1754(6.4 \%)$ of contacts. Table 3 shows the proportion of each contact outcome by age group.

There were a total of 9633 prescriptions issued at 7840 (28.6\%) contacts. In total, 5598 (29.5\%) individual children received prescriptions. 5656 (58.7\%) prescriptions were for antibiotics, and these were issued in 5420 (19.7\%) of contacts. Of contacts resulting in antibiotic prescription, 2278 of these contacts $(42.0 \%)$ had Respiratory codes (R), 1215 (22.4\%) had Ear codes $(\mathrm{H})$ and 778 (14.4\%) had Skin codes (S) (Table 4).

Prescriptions for asthma were the next most common with $852(8.8 \%)$ prescriptions for inhaled asthma medication and devices issued in 567 (2.1\%) contacts (Table 5). These included 529 (5.5\%) prescriptions for bronchodilators, and 90 (0.9\%) prescriptions for inhaled steroids. Steroid (oral and topical) prescriptions were also common with 679 (7.0\%) prescriptions issued in $664(2.4 \%)$ contacts.

\section{Discussion}

\section{Summary of findings}

Over a quarter $(26.69 \%)$ of contacts with the Oxfordshire OOH GP service between December 2014 and November 2015 were for children under the age of 18 . Of these, the majority (65.5\%) were for children aged under 5 years. There were more male than female patients amongst the under $5 \mathrm{~s}$, but amongst teenagers almost two thirds of the contacts were for female patients.

In over $40 \%$ of contacts there was no onward referral, requirement for GP follow up, or prescriptions, indicating that the primary clinical output of the contact was advice or reassurance. The proportion of these contacts was highest amongst the youngest age group (47.9\%) and fell in each subsequent age group. Antibiotics were prescribed in $19.7 \%$ of contacts, most commonly linked with ear, respiratory, and skin conditions.

During the week, the majority of contacts were in the evening, with a peak between 18:30 and 21:30. At the weekend, there was an early peak of contacts at 09:00 and a second, higher peak between the hours of 19:00 and 21:00.

Children presented most commonly with respiratory conditions. The most common ICPC code was an upper respiratory tract infection. Other common codes were unspecified viral diseases, tonsillitis and acute otitis media. There were few contacts with musculoskeletal or psychological complaints.

\section{Comparison with the literature}

In the UK research into paediatric use of NHS services has focused on unscheduled urgent care in Urgent Care 

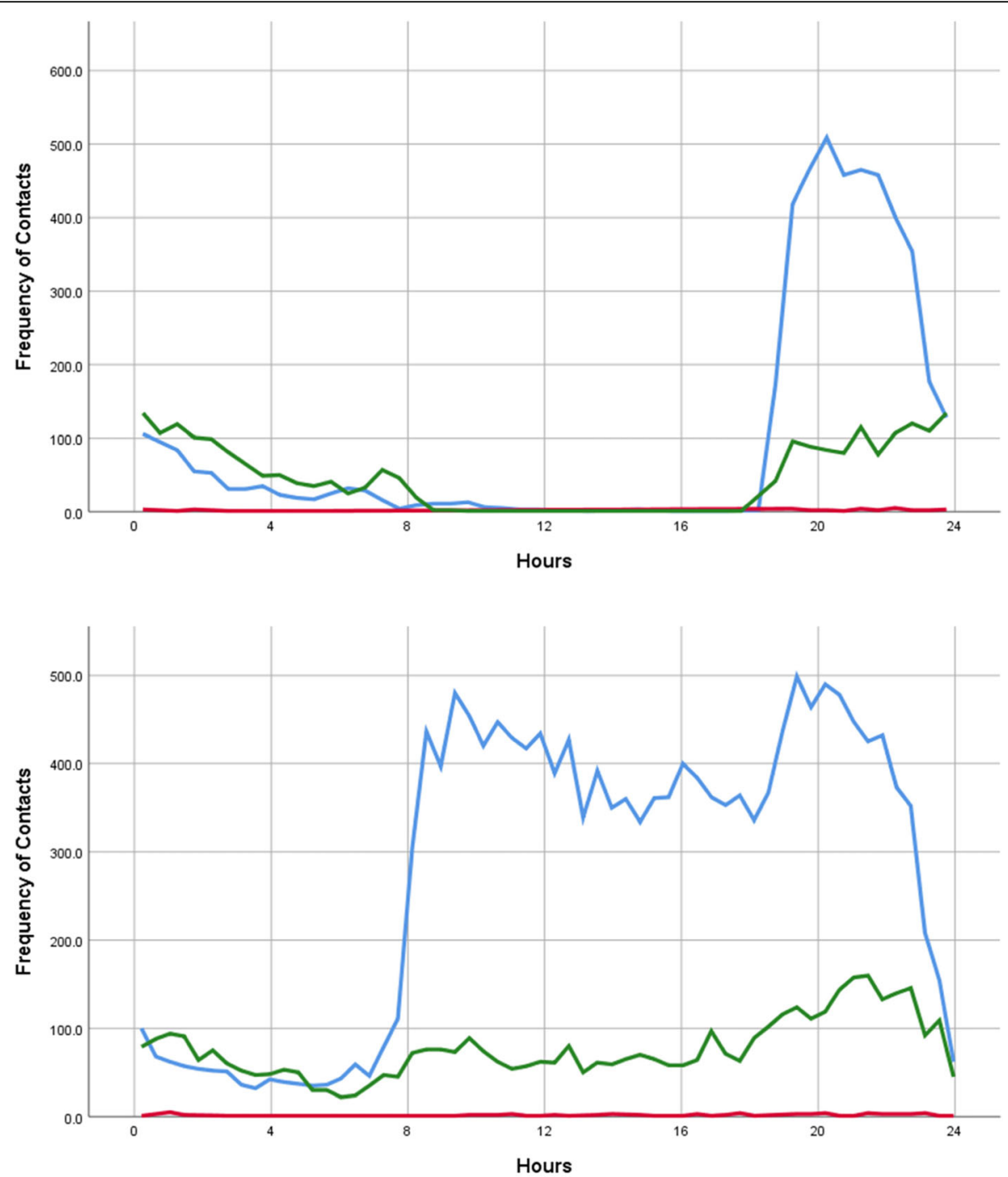

Fig. 3 Line graph by Final Contact Type showing the frequency of contacts by contact time with the $\mathrm{OOH}$ service through the day (top) during the week excluding Bank Holidays, and (bottom) at the weekend and on Bank Holidays (lower). Blue = "Base visit", Green = "Telephone Consultation", Red = "Home visit"

Centres (UCCs) and the Emergency Department (ED). Use of health services is highest amongst the youngest children [10, 17]. In 2011-12, one in three children aged under five visited the ED compared with $17 \%$ of children aged 5-14 [10]. This use peaks at 18:00 on weekdays, although not at weekends [10]. Amongst children under 5 the most common complaints to a UCC are respiratory system, infectious, or parasitic diseases [11]. In contrast, older children, especially those aged over 15 [11], use primary care services less, but present more commonly to UCCs with musculoskeletal complaints [12]. Our findings suggest that the profile of paediatric demand on $\mathrm{OOH}$ GP is more similar to that of the ED than the UCC.

In Europe the proportion of paediatric contacts with OOH GP ranged from $1.9 \%$ in Switzerland to $33.3 \%$ in Denmark [13]. In Belgium, Denmark, the Netherlands, and Norway, contacts were highest for those in the $0-4$ age group [13]. This work found that musculoskeletal and respiratory problems were very common amongst patients aged $0-17$, as were 'general and unspecified' and 'ear related'. Our study also found that respiratory and ear conditions were common but musculoskeletal conditions were less common. This may be due to the co-location of over half of the Oxfordshire bases with a minor injuries unit which would typically assess musculoskeletal problems. Similarly, urgent patient problems related to psychological illnesses may be handled by parallel out-of-hours services. These differences may be interesting to explore further in the context of the remit of other OOH GP available in these countries.

There is limited research into the outcomes of paediatric consultations with OOH GP. One study of 
Table 2 The frequency and percentage of contacts with clinical codes falling into each ICPC Chapter

\begin{tabular}{|c|c|c|c|c|c|c|c|c|c|c|}
\hline \multirow[t]{3}{*}{ ICPC Chapter } & \multicolumn{10}{|c|}{ Age Group } \\
\hline & \multicolumn{2}{|l|}{$' 0^{\prime}$} & \multicolumn{2}{|l|}{$' 1-4{ }^{\prime}$} & \multicolumn{2}{|l|}{${ }^{\prime} 5-11^{\prime}$} & \multicolumn{2}{|l|}{$' 12+{ }^{\prime}$} & \multicolumn{2}{|c|}{$\begin{array}{l}\text { Total No. Contacts with } \\
\text { Clinical Category }\end{array}$} \\
\hline & Count & $\%$ & Count & $\%$ & Count & $\%$ & Count & $\%$ & Count & $\%$ \\
\hline R - Respiratory & 1942 & $31.6 \%$ & 4650 & $39.2 \%$ & 1917 & $31.3 \%$ & 771 & $22.9 \%$ & 9280 & $33.8 \%$ \\
\hline A - General and unspecified & 1603 & $26.1 \%$ & 2864 & $24.2 \%$ & 890 & $14.5 \%$ & 270 & $8.1 \%$ & 5627 & $20.5 \%$ \\
\hline D - Digestive & 1141 & $18.6 \%$ & 1465 & $12.3 \%$ & 995 & $16.2 \%$ & 580 & $17.2 \%$ & 4181 & $15.2 \%$ \\
\hline S - Skin & 478 & $7.8 \%$ & 1055 & $8.9 \%$ & 716 & $11.7 \%$ & 386 & $11.5 \%$ & 2635 & $9.6 \%$ \\
\hline $\mathrm{H}$ - Ear & 275 & $4.5 \%$ & 1052 & $8.9 \%$ & 684 & $11.1 \%$ & 198 & $5.8 \%$ & 2209 & $8.0 \%$ \\
\hline Process & 389 & $6.3 \%$ & 521 & $4.4 \%$ & 371 & $6.0 \%$ & 299 & $8.8 \%$ & 1580 & $5.6 \%$ \\
\hline U - Urological & 33 & $0.5 \%$ & 303 & $2.6 \%$ & 296 & $4.8 \%$ & 228 & $6.8 \%$ & 860 & $3.1 \%$ \\
\hline D/F - DNA/Failed encounter ${ }^{b}$ & 178 & $2.9 \%$ & 294 & $2.5 \%$ & 122 & $2.0 \%$ & 94 & $2.8 \%$ & 688 & $2.5 \%$ \\
\hline F - Eye & 237 & $3.9 \%$ & 276 & $2.3 \%$ & 92 & $1.5 \%$ & 62 & $1.9 \%$ & 667 & $2.4 \%$ \\
\hline L - Musculoskeletal & 20 & $0.3 \%$ & 95 & $0.8 \%$ & 160 & $2.6 \%$ & 197 & $5.9 \%$ & 472 & $1.7 \%$ \\
\hline N - Neurological & 94 & $1.5 \%$ & 89 & $0.8 \%$ & 100 & $1.6 \%$ & 139 & $4.2 \%$ & 422 & $1.5 \%$ \\
\hline Y - Male Genital & 11 & $0.2 \%$ & 124 & $1.0 \%$ & 69 & $1.1 \%$ & 23 & $0.7 \%$ & 227 & $0.8 \%$ \\
\hline P - Psychological & 101 & $1.6 \%$ & 10 & $0.1 \%$ & 16 & $0.3 \%$ & 82 & $2.4 \%$ & 209 & $0.6 \%$ \\
\hline X - Female Genital & 11 & $0 \%$ & 55 & $1 \%$ & 33 & $1 \%$ & 74 & $2 \%$ & 173 & $0.6 \%$ \\
\hline W - Pregnancy, Childbearing, Family Planning & 1 & $0.0 \%$ & 0 & $0.0 \%$ & 0 & $0.0 \%$ & 75 & $2.2 \%$ & 76 & $0.3 \%$ \\
\hline B - Blood, Blood Forming Organs and Immune Mechanism & 6 & $0.1 \%$ & 27 & $0.2 \%$ & 18 & $0.3 \%$ & 7 & $0.2 \%$ & 58 & $0.2 \%$ \\
\hline T - Endocrine/Metabolic and Nutritional & 8 & $0.1 \%$ & 18 & $0.2 \%$ & 9 & $0.1 \%$ & 17 & $0.5 \%$ & 52 & $0.2 \%$ \\
\hline K - Cardiovascular & 3 & $0.0 \%$ & 5 & $0.0 \%$ & 11 & $0.2 \%$ & 31 & $0.9 \%$ & 50 & $0.2 \%$ \\
\hline Z - Social Problems & 0 & $0.0 \%$ & 2 & $0.0 \%$ & 2 & $0.0 \%$ & 3 & $0.1 \%$ & 7 & $0.0 \%$ \\
\hline Total & 6531 & * 1 & 2,905 & * & 6501 & * & 3536 & * & 29,473 & * \\
\hline
\end{tabular}

*Total percentages are not given. Some contacts have clinical code falling into more than one clinical category meaning the total percentages will be above $100 \%$

${ }^{\mathrm{b}}$ Code created in addition to ICPC codes to reflect failed encounters and those where patients did not attend (DNA)

consultations for fever amongst children consulting with an $\mathrm{OOH}$ GP service in the Netherlands found that $92 \%$ of contacts were managed without referral to secondary care [14]. In our study the equivalent figure was $93.6 \%$.
Antibiotics were prescribed in $19.7 \%$ of contacts in this study, primarily for respiratory, ear, and skin conditions. Antibiotic prescribing has previously been associated with $15 \%$ of all contacts with the UK OOH GP service, and $18.0 \%$ of contacts for individuals under the age of

Table 3 Frequency and percentage of contact outcomes by age group.

\begin{tabular}{|c|c|c|c|c|c|c|c|c|c|c|}
\hline \multirow[t]{3}{*}{ Contact Outcome } & \multicolumn{8}{|c|}{ Age Group } & \multirow{2}{*}{\multicolumn{2}{|c|}{$\begin{array}{l}\text { Total No. } \\
\text { Contacts }\end{array}$}} \\
\hline & \multicolumn{2}{|l|}{$0^{\prime}$} & \multicolumn{2}{|l|}{ '1-4' } & \multicolumn{2}{|l|}{ '5-11' } & \multicolumn{2}{|l|}{ '12+' } & & \\
\hline & Count & $\%$ & Count & $\%$ & Count & $\%$ & Count & $\%$ & Count & $\%$ \\
\hline No Follow Up or Prescription & 2941 & $47.9 \%$ & 5049 & $42.6 \%$ & 2282 & $37.3 \%$ & 1087 & $32.5 \%$ & 11,359 & $41.4 \%$ \\
\hline No Follow Up with Prescription & 671 & $10.9 \%$ & 2122 & $17.9 \%$ & 1319 & $21.6 \%$ & 682 & $20.4 \%$ & 4794 & $17.5 \%$ \\
\hline Patient Advised to Contact Own GP & 1782 & $29.0 \%$ & 3548 & $29.9 \%$ & 1943 & $31.8 \%$ & 1121 & $33.5 \%$ & 8394 & $30.6 \%$ \\
\hline Referred to A\&E & 259 & $4.2 \%$ & 449 & $3.8 \%$ & 215 & $3.5 \%$ & 168 & $5.0 \%$ & 1091 & $4.0 \%$ \\
\hline Admitted to Hospital & 218 & $3.6 \%$ & 246 & $2.1 \%$ & 114 & $1.9 \%$ & 85 & $2.5 \%$ & 663 & $2.4 \%$ \\
\hline Other referral & 121 & $2.0 \%$ & 181 & $1.5 \%$ & 137 & $2.2 \%$ & 120 & $3.6 \%$ & 559 & $2.0 \%$ \\
\hline No contact & 101 & $1.6 \%$ & 182 & $1.5 \%$ & 75 & $1.2 \%$ & 51 & $1.5 \%$ & 409 & $1.5 \%$ \\
\hline Own GP to contact patient & 33 & $0.5 \%$ & 49 & $0.4 \%$ & 18 & $0.3 \%$ & 30 & $0.9 \%$ & 130 & $0.5 \%$ \\
\hline Other & 10 & $0.2 \%$ & 26 & $0.2 \%$ & 15 & $0.2 \%$ & 5 & $0.1 \%$ & 56 & $0.2 \%$ \\
\hline Total & 6136 & $100 \%$ & 11,852 & $100 \%$ & 6118 & $100 \%$ & 3349 & $100 \%$ & 27,455 & $100 \%$ \\
\hline
\end{tabular}


Table 4 Count and \% for each ICPC Chapter in contacts resulting in an antibiotic prescription

\begin{tabular}{lcc}
\hline ICPC Chapter & Count & \% Contacts receiving an antibiotic \\
\hline R - Respiratory & 2278 & $42.0 \%$ \\
H - Ear & 1215 & $22.4 \%$ \\
S - Skin & 778 & $14.4 \%$ \\
U - Urological & 476 & $8.8 \%$ \\
A - General and unspecified & 470 & $8.7 \%$ \\
F - Eye & 330 & $6.1 \%$ \\
D - Digestive & 129 & $2.4 \%$ \\
Process & 121 & $2.2 \%$ \\
Y - Male Genital & 98 & $1.8 \%$ \\
L - Musculoskeletal & 25 & $0.0 \%$ \\
X - Female Genital & 18 & $0.0 \%$ \\
B - Blood, Blood Forming Organs and Immune Mechanism & 12 & $0.0 \%$ \\
N - Neurological & 11 & $0.0 \%$ \\
K - Cardiovascular & 2 & $0.0 \%$ \\
W - Pregnancy, Childbearing, Family Planning & 2 & $0.0 \%$ \\
P - Psychological & 1 & $0.0 \%$ \\
T - Endocrine/Metabolic and Nutritional & 0 & $0.0 \%$ \\
Z - Social Problems & 0 & $0.0 \%$ \\
D/F - DNA/Failed Encounter & $0 \%$ & \\
\hline
\end{tabular}

Table 5 Count and \% of prescribed items by category

\begin{tabular}{lcc}
\hline Prescription Category & Count & $\%$ \\
\hline Antibiotic & 5656 & $58.7 \%$ \\
Inhaled Asthma Medication And Devices & 852 & $8.8 \%$ \\
Steroid & 679 & $7.0 \%$ \\
Analgesia & 533 & $5.5 \%$ \\
Anti-Infective & 405 & $4.2 \%$ \\
Allergy & 357 & $3.7 \%$ \\
Topical Treatment & 327 & $3.4 \%$ \\
Gastrointestinal Disease Medication & 308 & $3.2 \%$ \\
Laxative & 230 & $2.4 \%$ \\
Miscellaneous & 137 & $1.4 \%$ \\
Contraception & 39 & $0.4 \%$ \\
Antiemetic & 33 & $0.3 \%$ \\
Psychiatric Medication & 28 & $0.3 \%$ \\
Epilepsy & 17 & $0.2 \%$ \\
Diabetes Care & 10 & $0.1 \%$ \\
Diabetes & 7 & $0.1 \%$ \\
Dressing & 5 & $0.1 \%$ \\
Immunosuppression & 4 & $0.0 \%$ \\
Formula & 4 & $0.0 \%$ \\
Cardiac Medication & 2 & $0.0 \%$ \\
\hline & &
\end{tabular}

18 [18]. Although our data were from the same population, it was from a later time period; reasons for a higher antibiotic prescription rate are unclear. Qualitative work has revealed that GPs have a lower threshold for prescribing $\mathrm{OOH}$ [19]. They raised concerns including safety, a lack of background knowledge about patients in an $\mathrm{OOH}$ GP setting and a lack of availability of diagnostics [19].

\section{Strength and limitations}

To our knowledge this is the first study to explore in detail paediatric demand on a UK OOH GP service. It uses a large dataset of 27,455 contacts. However, as the dataset is limited to Oxfordshire, our results may not be generalisable to the UK population as a whole. Oxfordshire is, on the whole, less deprived than the UK, and our methods should be replicated in other regions with different populations and care models. These data also precede recent extended access schemes which may alter how people navigate the health services.

\section{Implications for research and practice}

We found that $41.4 \%$ of contacts were 'advice only'. Whilst these contacts may have been appropriate, this highlights the need for research exploring the content and main function of these consultations, and reviewing whether alternative sources of advice could offer a safe substitute. This also suggests that nurse practitioners 
and paramedics who do not prescribe could be part of the team offering paediatric assessment with appropriate training.

Antibiotics were prescribed in $19.7 \%$ of contacts. UK $\mathrm{OOH}$ GP is associated with a disproportionately high rate of antibiotic prescribing [20], representing $5 \%$ of prescriptions from primary care despite only $1 \%$ of GP consultations occurring out-of-hours. In the Netherlands the appropriateness of antibiotic prescribing in OOH GP is comparable to in-hours care [21], but the extent to which this is true in the UK is unclear and could be a focus of future research. Point of care CRP testing has been shown to be feasible in a UK OOH primary care service [22], however, its role in reducing prescribing for acute respiratory illness in paediatrics remains unclear in this setting [23].

Finally, our study took a clinician perspective on contacts with $\mathrm{OOH}$ GP linking the reason for contact with the clinical codes applied during the consultation. Qualitative research exploring the process by which parents make decisions to consult $\mathrm{OOH}$ GP specifically will deepen our understanding of these consultations and how patients can be best supported. This is of specific interest for general and respiratory illnesses amongst younger children.

\section{Conclusions}

We found that paediatric contacts with the Oxfordshire $\mathrm{OOH}$ GP service were predominantly in younger age groups and in the early evening with $19.7 \%$ resulting in an antibiotic prescription. Almost half of the contacts were advice-only appointments, and further research should consider how patients making these appointments can be best supported.

\section{Supplementary information}

Supplementary information accompanies this paper at https://doi.org/10. 1186/s12875-020-01205-x.

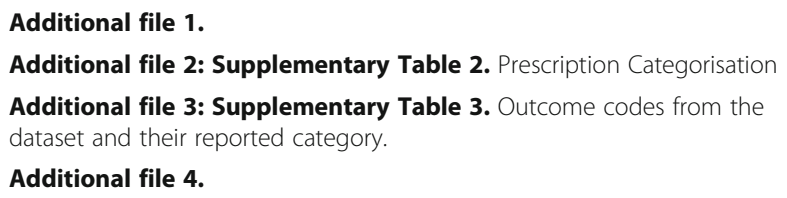

\section{Abbreviations}

OOH GP: Out-of-hours general practice; ED: Emergency department; IQR: Inter quartile range; UCC: Urgent care centre; ICPC: International classification of primary care; NOS: Not otherwise specified; IMD: Index of Multiple Deprivation

\section{Acknowledgments}

This work is supported by Oxford University Clinical Academic Graduate School and the National Institute for Health Research (NIHR) Community Healthcare MedTech and In Vitro Diagnostics Co-operative and NIHR ARC West Midlands. The views expressed are those of the author(s) and not necessarily those of the NHS, the NIHR or the Department of Health and Social Care.

\section{Authors' contributions}

$\mathrm{DL}, \mathrm{GH}$ and $\mathrm{GE}$ conceived of and designed the study, $\mathrm{HH}, \mathrm{GH}, \mathrm{GE}, \mathrm{CB}$ and $\mathrm{RB}$ contributed to the acquisition, analysis, and interpretation of the data. All authors have reviewed and approved the manuscript.

\section{Funding}

This project was funded by an early career research grant from Oxford University Clinical Academic Graduate School. GH, GE, CB, and DL are funded by the National Institute for Health Research (NIHR) Community Healthcare MedTech and In Vitro Diagnostics Co-operative at Oxford Health NHS Foundation Trust. This project was supported by the NIHR Applied Research Collaboration (ARC) West Midlands.

The views expressed are those of the authors and not necessarily those of the NIHR or the Department of Health and Social Care.

The funding bodies had no role in the study design, the collection, analysis, and interpretation of data, or in writing the manuscript.

Availability of data and materials

No data available. Data sharing permissions are not in place.

\section{Ethics approval and consent to participate}

This was a service evaluation prospectively approved by Oxford Health NHS Foundation Trust.

\section{Consent for publication}

All authors have consented to the publication of this manuscript.

\section{Competing interests}

The authors declare that they have no competing interests.

\section{Author details}

${ }^{1}$ Nuffield Department of Primary Care Health Sciences, Radcliffe Observatory Quarter, Woodstock Road, Oxford OX2 6GG, England. 'Birmingham Children's Hospital, Steelhouse Lane, Birmingham B4 6NH, England. ${ }^{3}$ Oxford Health NHS Foundation Trust, Warneford Hospital, Warneford Lane, Oxford OX3 7JX, England. ${ }^{4}$ Institute of Applied Health Research, College of Medical and Dental Sciences, Murray Learning Centre, University of Birmingham, Edgbaston, Birmingham B15 2TT, England.

Received: 5 September 2019 Accepted: 22 June 2020

Published online: 14 July 2020

\section{References}

1. NHS Digital. Hospital Accident and Emergency Activity, 2016-17. NHS Digit [Internet]. 2017; Available from: https://digital.nhs./catalogue/PUB30112.

2. France NP, Craze JL. Emergency Medicine. Arch Dis Child. 2006;91(Suppl 1): A28-30.

3. Sands R, Shanmugavadivel D, Stephenson T, Wood D. Medical problems presenting to paediatric emergency departments: 10 years on. Emerg Med J. 2012;29(5):379-82.

4. McHale P, Wood S, Hughes K, Bellis MA, Demnitz U, Wyke S. Who uses emergency departments inappropriately and when - a national crosssectional study using a monitoring data system. BMC Med. 2013;11(1):1-9.

5. Partnership HL, London T. New acute models of care for children and young people. 2017;(April).

6. Viner RM, Blackburn F, White F, Mannie R, Parr T, Nelson S, et al. The impact of out-of-hospital models of care on paediatric emergency department presentations. Arch Dis Child. 2018;103(2):128-36.

7. Baker M, Thomas M, Mawby R. The Future of GP Out of Hours Care. 2014; Available from: http://www.rcgp.org.uk/policy/ /media/Files/Policy/A-Zpolicy/RCGP-The-Future-of-GP-Out-of-Hours-Care-2015.ashx.

8. Brettell R, Fisher R, Hunt H, Garland S, Lasserson D, Hayward G. What proportion of patients at the end of life contact out-of-hours primary care? A data linkage study in Oxfordshire. BMJ Open. 2018;8:e020244. https://doi. org/10.1136/bmjopen-2017-020244.

9. National Audit Office. Out-of-hours GP services in England. 2014; (September). Available from: http://www.nao.org.uk/report/hours-gpservices-england-2/. 
10. Cecil E, Bottle A, Cowling TE, Majeed A, Wolfe I, Saxena S. Primary care access, emergency department visits, and unplanned short hospitalizations in the UK. Pediatrics 2016;137(2):e20151492. Available from: http://pediatrics. aappublications.org/cgi/doi/https://doi.org/10.1542/peds.2015-1492.

11. Gnani S, Morton S, Ramzan F, Davison M, Ladbrooke T, Majeed A, et al. Healthcare use among preschool children attending GP-led urgent care centres: a descriptive, observational study. BMJ Open. 2016;6(6):1-8.

12. Gnani S, McDonald H, Islam S, Ramzan F, Davison M, Ladbrooke T, et al. Patterns of healthcare use among adolescents attending an urban general practitioner-led urgent care Centre. Emerg Med J. 2014.

13. Huibers LAMJ, Moth G, Bondevik GT, Kersnik J, Huber CA, Christensen MB, et al. Diagnostic scope in out-of-hours primary care services in eight European countries: an observational study. BMC Fam Pract. 2011;12:30 Available from: http://www.pubmedcentral.nih.gov/articlerender.fcgi?artid= 3114765\&tool=pmcentrez\&rendertype=abstract.

14. De Bont EGPM, Lepot JMM, Hendrix DAS, Loonen N, Guldemond-Hecker Y, Dinant GJ, et al. Workload and management of childhood fever at general practice out-of-hours care: an observational cohort study. BMJ Open. 2015; 5(5):1-6.

15. Lous J, Moth G, Huibers L, et al. Preschool children in Danish out-of-hours primary care: a one-year descriptive study of face-to-face consultations. BMC Fam Pract. 2019;20:36. https://doi.org/10.1186/s12875-019-0922-y.

16. Khan NF, Harrison SE, Rose PW. Validity of diagnostic coding within the general practice research database: a systematic review. $\mathrm{Br} J \mathrm{Gen}$ Pract. 2010;60(572):199-206.

17. Hobbs FDR, Bankhead C, Mukhtar T, Stevens S, Perera-Salazar R, Holt T, et al. Clinical workload in UK primary care: a retrospective analysis of 100 million consultations in England, 2007-14. Lancet. 2016;387(10035):2323-30.

18. Hayward GN, Fisher RFR, Spence GT, Lasserson DS. Increase in antibiotic prescriptions in out-of-hours primary care in contrast to in-hours primary care prescriptions: service evaluation in a population of 600000 patients. J Antimicrob Chemother 2016;71(9):2612-2619. Available from: http://www. jac.oxfordjournals.org/lookup/doi/https://doi.org/10.1093/jac/dkw189.

19. Colliers A, Coenen S, Remmen R, Philips H, Anthierens S. How do general practitioners and pharmacists experience antibiotic use in out-of-hours primary care? An exploratory qualitative interview study to inform a participatory action research project. BMJ Open. 2018;8(9):e023154 Available from: http://www.ncbi.nlm.nih.gov/pubmed/30269072\%0Ahttp://www. pubmedcentral.nih.gov/articlerender.fcgi?artid=PMC6169767.

20. Edelstein M, Agbebiyi A, Ashiru-Oredope D, Hopkins S. Trends and patterns in antibiotic prescribing among out-of-hours primary care providers in England, 2010-14. J Antimicrob Chemother. 2017;72(12):3490-5.

21. Debets VE, Verheij TJM. Velden AW Van Der. Antibiotic prescribing during office hours and out-of-hours. Br J Gen Pract. 2017;67(656):178-86. https:// pubmed.ncbi.nlm.nih.gov/28232364/.

22. Van Den Bruel A, Jones C, Thompson M, Mant D. C-reactive protein pointof-care testing in acutely ill children: a mixed methods study in primary care. Arch Dis Child. 2016;101(4):382-6 Available from: http://onlinelibrary. wiley.com/o/cochrane/clcentral/articles/455/CN-01168455/frame.html.

23. Lemiengre MB, Verbakel JY, Colman R, De Burghgraeve T, Buntinx $F$, Aertgeerts B, et al. Reducing inappropriate antibiotic prescribing for children in primary care: a cluster randomised controlled trial of two interventions. $\mathrm{Br}$ J Gen Pract. 2018;68(668):e204-10.

\section{Publisher's Note}

Springer Nature remains neutral with regard to jurisdictional claims in published maps and institutional affiliations.

Ready to submit your research? Choose BMC and benefit from:
- fast, convenient online submission
- thorough peer review by experienced researchers in your field
- rapid publication on acceptance
- support for research data, including large and complex data types
- gold Open Access which fosters wider collaboration and increased citations
- maximum visibility for your research: over 100M website views per year
At BMC, research is always in progress.
Learn more biomedcentral.com/submissions

